\title{
Impacto do tipo de misturador e do tempo de mistura nas propriedades de argamassas industrializadas
}

\author{
Impact of the mixer and time of mixing on the properties
} of industrialized mortar

\begin{tabular}{r}
\hline \\
Roberto Cesar de Oliveira \\
Romano \\
Departamento de Engenharia Civil, \\
Escola Politécnica \\
Universidade de São Paulo \\
Av. Professor Almeida Prado, Trav. 2, \\
n. 83, Cidade Universitária \\
Caixa Postal 61.548 \\
São Paulo - SP - Brasil \\
CEP: 05424-970 \\
Tel.: (11) 3091-5382 \\
E-mail: rcorjau@gmail.com \\
Harry Schreurs \\
Escola Politécnica \\
Departamento de Engenharia Civil, \\
Universidade de São Paulo \\
E-mail: harry.schreurs@gmail.com
\end{tabular}

Fernanda Belizário da Silva Departamento de Engenharia Civil, Escola Politécnica Universidade de São Paulo E-mail: fernanda.belizario@gmail.com

Fábio Alonso Cardoso Departamento de Engenharia Civil, Escola Politécnica Universidade de São Paulo fabio.alonso.cardoso@poli.usp.br

Mercia Maria Semensato Bottura de Barros Departamento de Engenharia Civil, Escola Politécnica Universidade de São Paulo E-mail: mercia.barros@poli.usp.br

Vanderley Moacyr John Departamento de Engenharia Civil, Escola Politécnica

Universidade de São Paulo E-mail: vanderley.john@poli.usp.br

Rafael Giuliano Pileggi Departamento de Engenharia Civil, Escola Politécnica

Universidade de São Paulo

E-mail: rafael.pileggi@poli.usp.br

Recebido em 15/07/09 Aceito em 16/10/09

\section{Roberto Cesar de Oliveira Romano \\ Harry Schreurs \\ Fernanda Belizário da Silva \\ Fábio Alonso Cardoso \\ Mercia Maria Semensato Bottura de Barros \\ Vanderley Moacyr John \\ Rafael Giuliano Pileggi}

\section{Resumo}

$\Delta$

rgamassas industrializadas anidras usualmente empregam aditivos em suas formulações, sendo muito comum o uso de incorporadores de ar. Apesar do rigor da produção deste material em ambiente fabril, variações nas condições de preparo em obra podem afetar o teor de ar no revestimento. Usualmente, as argamassas são processadas manualmente em obras ou com o auxílio de equipamentos de mistura. Dessa forma, neste trabalho foi avaliado o impacto do tipo de equipamento e do tempo de mistura na incorporação de ar de argamassas industrializadas e o efeito nas propriedades após o endurecimento. Os resultados indicam que a incorporação de ar decorre da adequação entre o equipamento de mistura e a formulação da argamassa, sendo identificada diferença de sensibilidade das argamassas ao tipo de equipamento. Tal fato permite inferir que a alternativa para reduzir a variabilidade do teor de ar em obra depende do desenvolvimento de formulações com mínima sensibilidade ao processo de mistura.

Palavras-chave: Mistura. Argamassa. Ar incorporado. Resistência mecânica. Módulo de elasticidade.

\section{Abstract}

Industrialized rendering mortars usually employ additives in their formulations, most commonly air-entraining agents. In order to ensure quality and production scale, they are prepared in manufacturing units with precise control of the formulation and dosage of raw materials and additives. Despite the control in the production of this material in an industrial environment, variations in the mixing conditions may affect the level of air incorporation. On construction sites, mortars are usually either processed manually or with the use of mixing equipment. This study evaluates the impact of the type of equipment and mixing time on air incorporation in industrialized mortars and the effect on their properties after hardening. The results indicate that the incorporation of air results from the adjustment between the mixing equipment and the mortar formulation. Different sensibilities of mortars to the type of equipment have been identified. That fact indicates that an alternative to reduce variability on the level of air incorporation in building sites depends on the development of formulations with minimal sensibility to the mixing process.

Keywords: Mixture. Rendering mortar. Air incorporation. Mechanical strength. Modulus of elasticity. 


\section{Introdução}

A incorporação de ar em argamassas industrializadas é prática comum no setor construtivo, visto que permite melhorar a coesão, reduz a tendência à exsudação, melhora a plasticidade e possibilita reduzir a quantidade de água necessária para o amassamento, o que, possivelmente, diminui a retração plástica por secagem e reduz o módulo de elasticidade do revestimento endurecido (ALVES, 2002). Por isso, o tema vem sendo amplamente estudado ao longo dos anos (CASALI et al., 2001, 2003; MONTE; UEMOTO; SELMO, 2003; ROMANO et al., 2007a, 2007b).

Esses tipos de materiais são produzidos em unidades fabris com o controle preciso do proporcionamento das matérias-primas e aditivos empregados na formulação (CINCOTTO et al., 1999) mas, apesar do domínio da tecnologia e da química dos aditivos, a incorporação de ar em materiais cimentícios é ainda bastante empírica, e o uso de AIA tem sido apontado como um fator de complexidade operacional no processo (ROMANO et al., 2009). Sua presença nas composições as torna muito sensíveis ao processamento, temperatura, transporte, etc., e essas variáveis afetam diretamente as características dos materiais após o endurecimento, sendo, na prática, uma fonte de variabilidade.

Com isso, o difícil controle das propriedades dos materiais aerados tem muitas vezes desaconselhado a utilização dessa tecnologia em diversas aplicações no setor construtivo, ou seja, apesar das potenciais virtudes, a falta de controle no processamento dificulta o emprego de argamassas e concretos aerados como tipos de materiais sustentáveis.

Em obra, as argamassas geralmente são misturadas de duas formas: manual ou mecânica. Quando são misturadas manualmente, dificilmente é atingido o mesmo nível de desaglomeração e incorporação de ar obtido após a mistura mecânica, devido à menor eficiência, e a produtividade do revestimento aplicado é mais baixa. Assim, a mecanização da etapa de mistura no processo construtivo representa um avanço no processamento do revestimento.

Os dois tipos de equipamentos mais utilizados em obras para esse fim são as betoneiras (B) e os misturadores de eixo horizontal (EH). Entretanto, as diferenças conceituais entre os equipamentos impõem às argamassas distintas energias e tipos de mistura, interferindo diretamente na eficiência do processamento.
A diferença nos equipamentos e nos procedimentos de operação deles provavelmente contribui para que em obras seja verificada uma grande variabilidade no teor de ar em cada batelada de argamassas produzida (CHIA; ZHANG, 2007; DU; FOLLIARD, 2005; ROMANO et al., 2007a, 2007b; SURYAVANSHI; SWAMI, 2002), o que afeta diretamente o desempenho dos revestimentos após o endurecimento (CARASEK; SCARTEZINI, 1999), já que as alterações promovidas no estado fresco são refletidas nas propriedades no estado endurecido (ROMANO et al., 2009).

Sendo assim, o controle preciso da dosagem na formulação das argamassas industrializadas somente se fará percebido se as variáveis que afetam a mistura desses materiais também forem controladas, possibilitando o efetivo domínio do material produzido.

Dessa forma, este trabalho foi realizado com o objetivo de avaliar o impacto do tipo de equipamento e do tempo de mistura na incorporação de ar de argamassas industrializadas e o efeito gerado nas propriedades do revestimento após o endurecimento.

\section{Materiais e métodos}

Neste trabalho foram utilizadas três argamassas de revestimento industrializadas, fornecidas por produtores nacionais, com distintas características granulométricas e físicas, conforme apresentado, respectivamente, na Figura 1 e na Tabela 1.

\section{Procedimentos de mistura}

As argamassas foram misturadas em dois equipamentos com distintas capacidades volumétricas e tipos de solicitação durante a mistura. Os procedimentos utilizados são descritos a seguir.

\section{Argamassadeira de Eixo Horizontal}

$40 \mathrm{~kg}$ de pó foram colocados na argamassadeira, da marca Consolid (com capacidade para $60 \mathrm{~L}$ de argamassa), e, em seguida, toda a água foi adicionada (no teor indicado pelo fabricante), numa vazão de $200 \mathrm{~g} / \mathrm{s}$. Para garantir a adição homogênea da água em toda a argamassa, foi utilizada uma bandeja com furos projetada especialmente para este trabalho. O esquema do equipamento utilizado é apresentado na Figura 2a. 
Nesse tipo de equipamento a lâmina de mistura (tipo naben blade) (PERRY, 1997) empurra as camadas mais externas de argamassa para o interior da massa, impondo intenso cisalhamento ao material e facilitando o rompimento dos aglomerados e a entrada de ar.

\section{Betoneira}

Toda a água, no teor indicado pelo fabricante, foi adicionada na betoneira (Formeq, com capacidade de 120 L), e, em seguida, $40 \mathrm{~kg}$ do pó (Figura 2b) foram adicionados com o equipamento desligado. $\mathrm{O}$ equipamento foi ligado, e a argamassa foi misturada pelos tempos propostos.

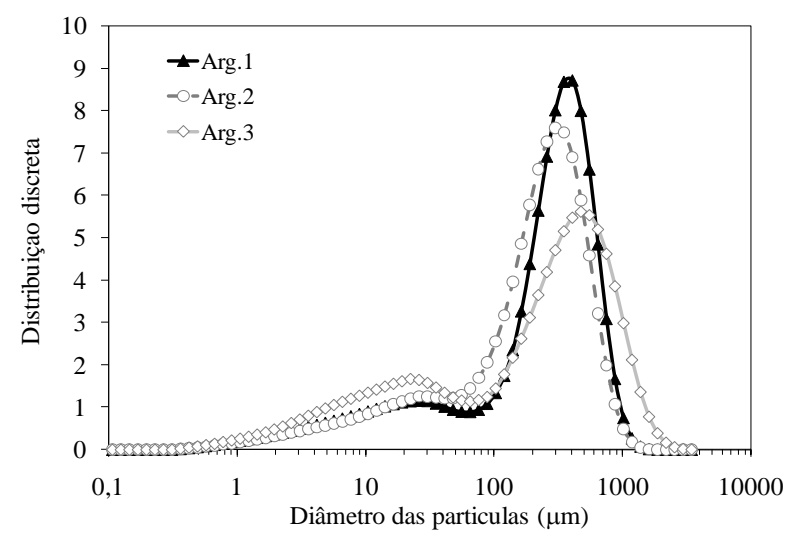

(a) Discreta
A mistura na betoneira ocorre após sucessivas quedas de parte da argamassa sobre o restante do material, encontrado na parte inferior do equipamento (FERRARIS, 2001). Por isso, a inclinação interfere diretamente na eficiência da mistura e incorporação de ar. Quanto mais horizontal for a posição do misturador, menor é a eficiência, pois menor quantidade de argamassa cai sobre o restante. Se a betoneira permanecer voltada para cima $\left(90^{\circ}\right)$, a eficiência é mais baixa ainda, pois não há queda. No entanto, para se atingir maior eficiência, é aconselhado que a inclinação seja de, no mínimo, $15^{\circ}$ (FERRARIS, 2001). Neste trabalho, a inclinação utilizada foi de cerca de $30^{\circ}$.

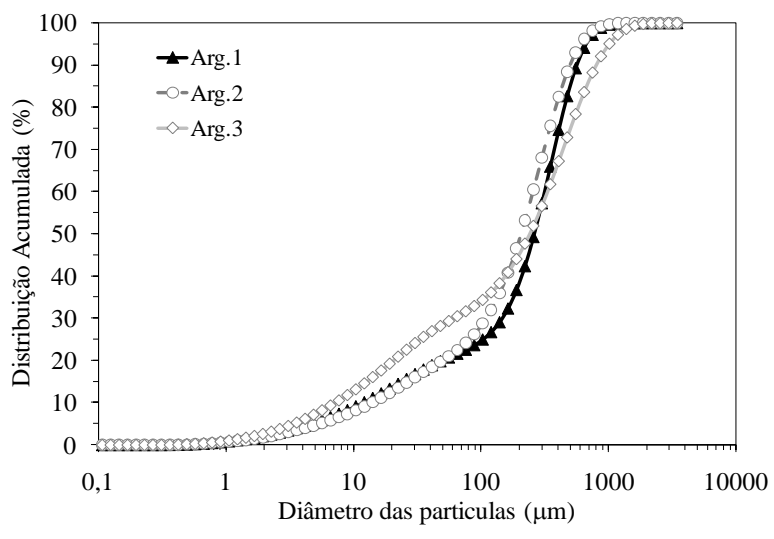

(b) Acumulada

Figura 1 - Distribuições granulométricas das argamassas

\begin{tabular}{l|c|c|c}
\hline \multicolumn{1}{c|}{ Propriedades } & Argamassa 1 & Argamassa 2 & Argamassa 3 \\
\hline Massa específica real - total $\left(\mathrm{kg} / \mathrm{dm}^{3}\right)$ & $2,79 \pm 0,10$ & $2,82 \pm 0,16$ & $2,82 \pm 0,02$ \\
Massa específica real - finos $\left(\mathrm{kg} / \mathrm{dm}^{3}\right)$ & $3,08 \pm 0,06$ & $3,06 \pm 0,05$ & $2,97 \pm 0,03$ \\
Finos $[<100 \mu \mathrm{m}(\%-\mathrm{p})]$ & 24,0 & 28,5 & 34,0 \\
Agregados $[>100 \mu \mathrm{m}(\%-\mathrm{p})]$ & 76,0 & 71,5 & 66,0 \\
$\mathrm{D}_{50}(\mu \mathrm{m})$ & 260 & 200 & 240 \\
$\mathrm{D}_{90}(\mu \mathrm{m})$ & 520 & 480 & 700 \\
Teor de água indicado $(\%-\mathrm{p})$ & 16,25 & 15,25 & 13,25 \\
\hline
\end{tabular}

Tabela 1 - Características físicas das argamassas utilizadas no trabalho

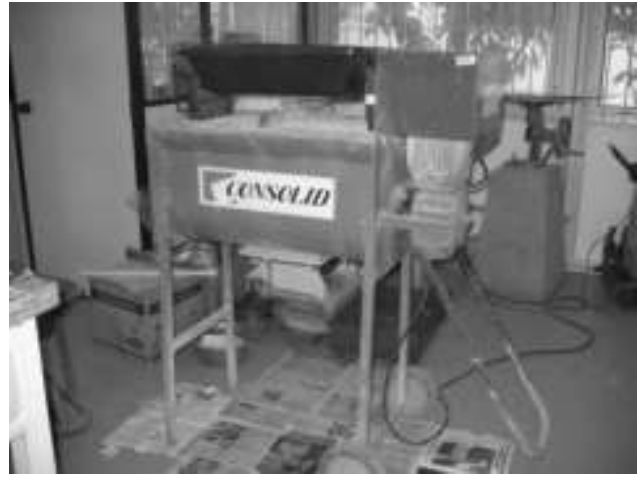

(a) Argamassadeira de eixo horizontal

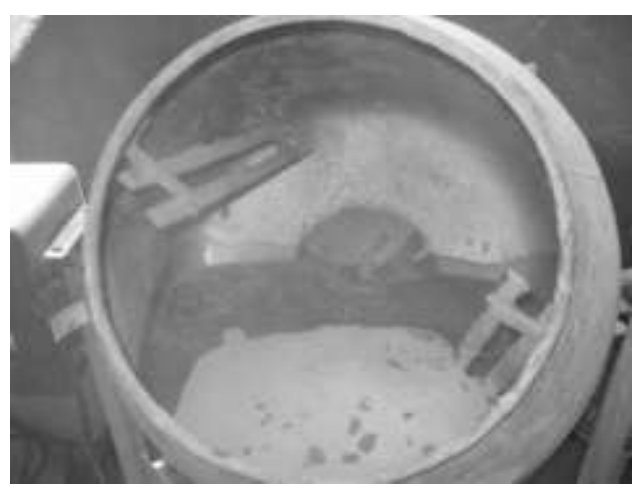

(b) Betoneira

Figura 2 - Equipamentos utilizados para a mistura das argamassas 
Como é comumente observado nas obras, o processamento das argamassas ocorre em diferentes equipamentos e, em muitos casos, por tempos de mistura distintos. Por isso, as argamassas foram misturadas por $2 \mathrm{~min}, 4 \mathrm{~min}$ e 6 min, para avaliação, também, do efeito do tempo de mistura na incorporação de ar e nas propriedades no estado endurecido.

\section{Avaliações no estado fresco}

\section{Reometria rotacional}

A caracterização reológica a partir de ensaio de fluxo foi realizada em um reômetro do tipo planetário (Figura 3a), com controle preciso da velocidade e aquisição do torque como resposta ao cisalhamento aplicado. Esse tipo de ensaio serve para avaliar as propriedades das argamassas no estado fresco, quantificando a energia necessária para o processamento. Também pode ser uma ferramenta útil para a adequação do material ao método de aplicação.

\section{Densidade e ar incorporado}

$\mathrm{O}$ ensaio foi realizado de acordo com a norma técnica NBR 13278 (ABNT, 2002), e os valores foram calculados a partir da densidade real do pó (obtida por picnometria de gás hélio). A Figura 3b ilustra o aparato utilizado para a realização do ensaio.

\section{Estado endurecido}

\section{Resistência a tração na flexão em três pontos}

A tensão de ruptura das argamassas foi quantificada de acordo com a norma técnica NBR

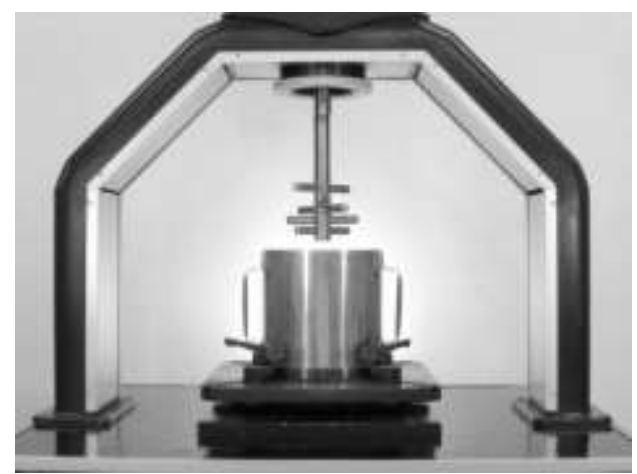

(a) Reômetro
13279 (ABNT, 2005), utilizando-se corpos-deprova com dimensões de $4 \mathrm{~cm}$ x $4 \mathrm{~cm}$ x $16 \mathrm{~cm}$. Em todos os casos foram rompidos nove corpos-deprova de cada sistema, para se ter uma média dos resultados e a dispersão dos valores.

\section{Módulo de elasticidade}

A medida foi realizada de acordo com a norma técnica britânica BS 1881 (BSI, 1986) - part 203, com um equipamento denominado "pulso-eco" (Pundit), com transdutores de freqüência $200 \mathrm{kHz}$ e seção transversal circular com diâmetro de 20 mm (acoplados com gel na superfície dos corposde-prova). Como no caso da resistência mecânica, foram avaliados nove corpos-de-prova de $4 \mathrm{~cm} \mathrm{x}$ $4 \mathrm{~cm} \times 16 \mathrm{~cm}$ para cada sistema.

\section{Resultados e discussões}

As argamassas foram avaliadas nos estados fresco e endurecido, e os resultados são apresentados a seguir.

\section{Estado fresco}

A quantificação do efeito da alteração do tipo de misturador e do tempo de mistura nas propriedades no estado fresco das argamassas foi feita a partir da determinação do teor de ar incorporado e por reometria rotacional. Os resultados são apresentados a seguir.

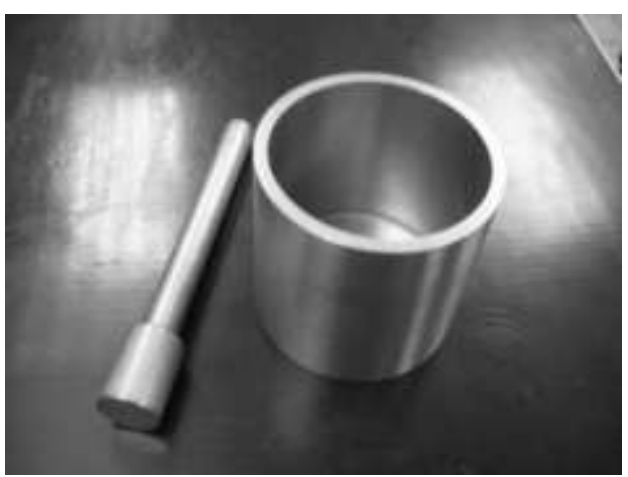

(b) Copo para determinação da densidade e do teor de ar incorporado

Figura 3 - Ilustração dos equipamentos utilizados para caracterização do estado fresco 


\section{Ar incorporado}

Os resultados de incorporação de ar das argamassas avaliadas demonstram que a variação no tempo de mistura gerou sensíveis alterações nas quantidades de ar incorporado. Na Figura 4 são apresentados os teores de ar incorporado e na Figura 5 as variações absolutas, em relação ao valor de ar incorporado após mistura por $2 \mathrm{~min}$ $\left(\mathrm{Ar}_{2,4}\right.$ ou $\left.6 \mathrm{~min}-\mathrm{Ar}_{2 \mathrm{~min}}\right)$, menor tempo utilizado no estudo.

A Argamassa 1, misturada na argamassadeira EH, apresentou a menor sensibilidade ao processamento (menor coeficiente angular entre todas as avaliações) mas, quando foi misturada na betoneira, a alteração no teor de ar foi a mais elevada de todas, mostrando que, se essa argamassa for processada em betoneira, deve-se ter maior cuidado com a etapa de mistura.

A Argamassa 2 apresentou níveis de ar muito maiores que nas demais argamassas, mas não apresentou a maior variação absoluta, que pode melhor representar a sensibilidade das argamassas à mistura. Quanto maior o coeficiente angular da reta, há um indicativo de maior sensibilidade da argamassa ao processamento, devido à maior variação na incorporação de ar.

Assim, pode-se inferir que a Argamassa 3, apesar de não ter apresentado os maiores teores de ar

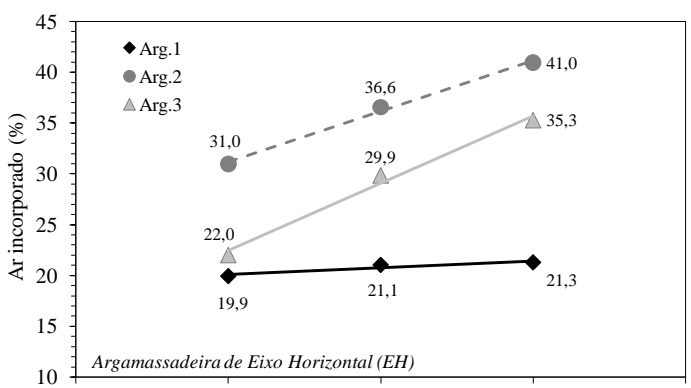

(a) Argamassadeira de eixo horizontal

Figura 4 - Teor de ar incorporado

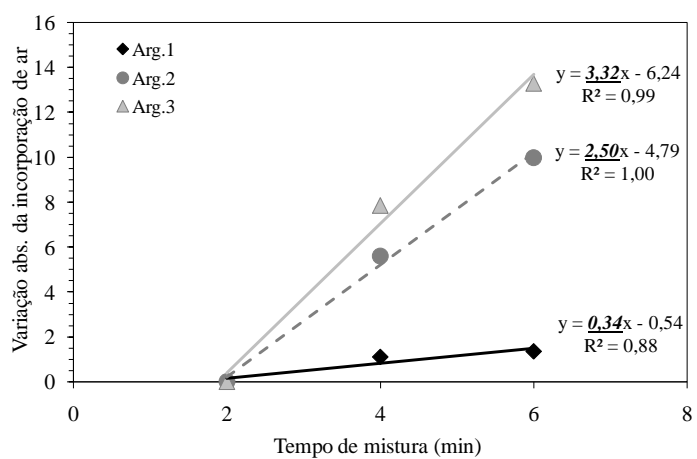

(a) Argamassadeira de eixo horizontal entre as argamassas avaliadas, apresenta maior sensibilidade ao processamento, principalmente quando é misturada na argamassadeira EH. Além disso, não foi possível quantificar o teor de ar nesta argamassa após a mistura na betoneira por $2 \mathrm{~min}$, já que a energia de mistura imposta pelo equipamento não foi suficiente para o rompimento dos aglomerados de partículas e, por isso, não tornou a argamassa adequada para aplicação. Mesmo assim, a variação absoluta, neste caso, entre 4 min e 6 min, já foi elevada.

O tempo de mistura foi a variável de maior impacto nos resultados. O aumento no tempo de processamento proporcionou um aumento linear na incorporação de ar. No entanto, o tipo de equipamento empregado também exerceu influência na incorporação de ar, mas não houve uma tendência clara de maior eficiência na incorporação de ar, uma vez que a Argamassa 1 teve comportamento distinto das demais, incorporando maior volume absoluto de ar quando foi misturada na betoneira.

Portanto, pode-se inferir que o controle na incorporação de ar depende da adequação da argamassa ao misturador, devendo o comportamento ideal ser o mais próximo possível do obtido para a Argamassa 1 misturada na argamassadeira EH.

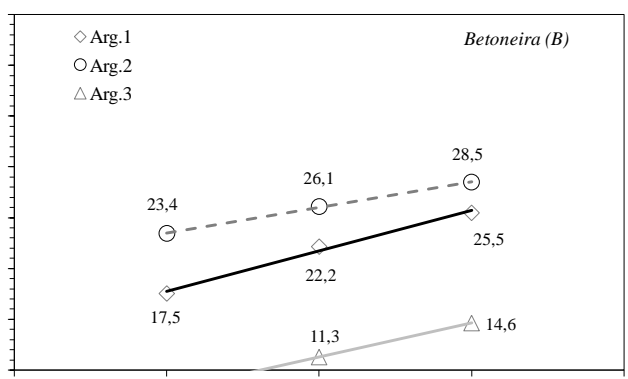

(b) Betoneira

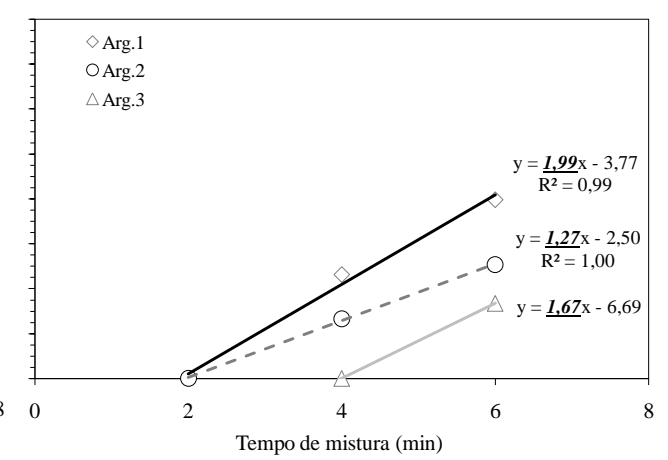

(b) Betoneira

Figura 5 - Variações nos teores de ar absolutos em função da mistura por 2 min 


\section{Reometria rotacional}

A caracterização da mistura pode ser um indicativo da qualidade e da produtividade da argamassa em obra. Maiores energias necessárias para o processamento das argamassas podem indicar menor produtividade, pois necessitam de maiores tempos de mistura ou de maiores esforços do profissional responsável pelo amassamento.

Na Figura 6a são apresentadas as "histórias" de mistura, e na $6 \mathrm{~b}$, as estimativas das energias de mistura (quantificadas a partir da área abaixo das curvas de torque $v s$ tempo).

A primeira etapa da mistura consiste na adsorção da água na superfície das partículas e, conseqüentemente, ocorre a formação dos aglomerados, devido às forças de interação de van de Waals, forças eletrostáticas entre posições de sítios com cargas opostas e forte interação ou ligação envolvendo as moléculas de água ou hidratos.

Essa aglomeração é responsável pela retenção de parte da água necessária para a mistura, que, caso a energia de cisalhamento não seja suficiente para o rompimento dos aglomerados, fica indisponível para hidratar a superfície das partículas de cimento e para fluidificar a mistura.

Na Figura 6a pode-se notar que, após a adição da água, a tendência natural de aglomeração das partículas faz com que o torque aumente, num primeiro instante, devido ao aprisionamento de água.

O final dessa primeira etapa da mistura é observado na Figura 6a, com a indicação das setas e, para cada argamassa, nota-se que o final da primeira etapa ocorre em um tempo distinto, sendo o tempo para a Argamassa 3 mais de duas vezes mais longo que para as demais.

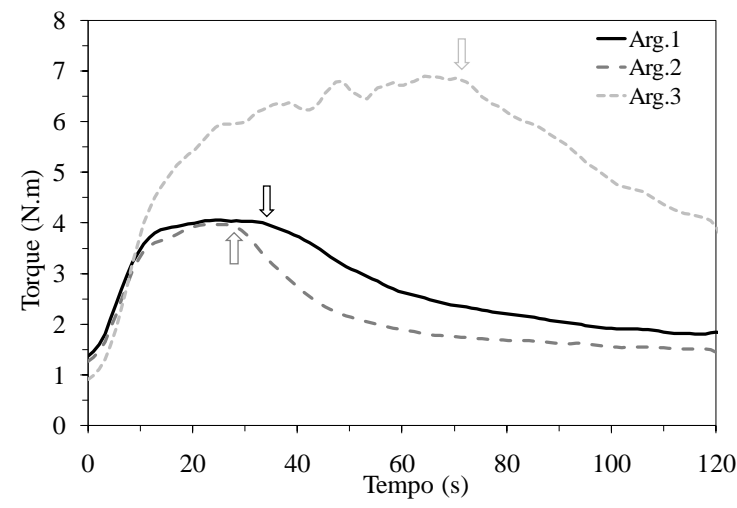

(a)
Com o passar do tempo, o rompimento dos aglomerados libera água para a mistura e ocasiona uma queda no torque, observado na Figura 6a, a partir das setas. A liberação da água dos aglomerados permite tanto a facilitação da mistura quanto a maior incorporação de ar, já que, para ser geradas as bolhas de ar, é necessária uma dispersão da pasta mínima.

Como pode ser visto, a Argamassa 3 necessita de maior energia para o rompimento dos aglomerados $\mathrm{e}$, consequientemente, para a mistura. É por isso que, nos menores tempos de processamento, o teor de ar incorporado nesta argamassa foi baixo, pois esta se encontrava muito aglomerada. No entanto, com o rompimento dos aglomerados, o ar foi incorporado mais rapidamente, conforme observado anteriormente.

Já as curvas de mistura da Argamassa 1 e da Argamassa 2 foram muito semelhantes até cerca de 30 seguntos e, a partir daí, a Argamassa 2 sempre atingiu níveis de torque menores que a Argamassa 1. As diferenças nos torques estão relacionadas com a maior incorporação de ar na Argamassa 2 e, conseqüentemente, com a maior separação dos agregados. Com isso a mistura é facilitada.

Sabe-se que, quanto maior o teor de matriz na formulação, maior será a área superficial da composição e, conseqüentemente, será necessária maior quantidade de água para o recobrimento das partículas e processamento do material. No entanto, na Argamassa 3, apesar de apresentar maior quantidade de finos que as demais, o teor de água indicado pelo fabricante foi menor. Isso resultou numa argamassa muito difícil de ser misturada, resultando em maior energia de mistura, 2,3 vezes maior que para a Argamassa 2 e 1,9 vez maior que para a Argamassa 1 .

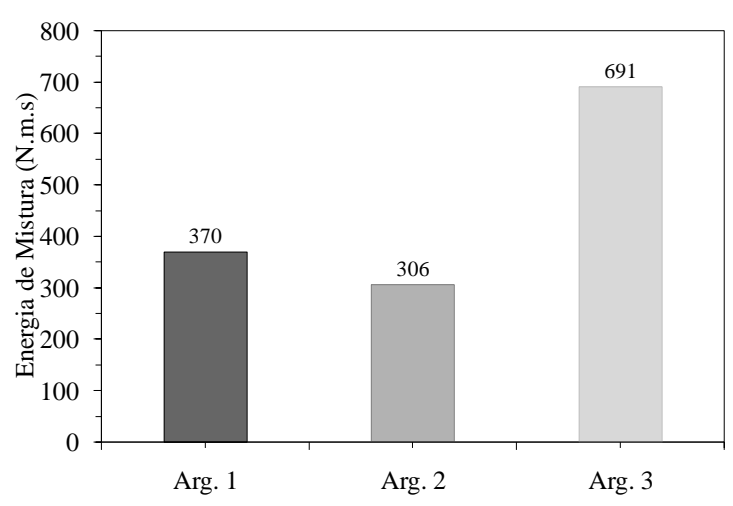

(b)

Obs: As setas indicam o início da desaglomeração das partículas

Figura 6 - Curvas de mistura das argamassas (a) e estimativas das energias de mistura (b), calculadas a partir das áreas abaixo das linhas do gráfico de torque vs tempo 
Em obra essa elevada energia de mistura pode indicar que a Argamassa 3 não apresenta elevada produtividade, já que é necessário maior tempo para o amassamento, para tornar a argamassa adequada ao uso.

\section{Estado endurecido}

Como visto na caracterização no estado fresco, a variação no tempo de mistura influenciou diretamente no teor de ar incorporado nas argamassas, o que pode afetar o desempenho dos revestimentos em uso. No entanto, dependendo da estabilidade do ar durante a moldagem, nem todo ar incorporado gera porosidade no corpo-de-prova após o endurecimento, devido à coalescência das bolhas. Assim, antes de se avaliarem as propriedades das argamassas após o endurecimento, foi avaliada a estabilidade do ar durante a moldagem.

Para isso, utilizou-se o procedimento descrito a seguir.

Após a completa secagem, os corpos-de-prova foram medidos e pesados. A partir do cálculo do volume e da massa, determinou-se a densidade volumétrica de cada $\mathrm{CP}\left(\rho_{\mathrm{vol}}\right)$.

Os CPs foram moídos e tiveram as densidades reais determinadas a partir de picnometria de gás He $\left(\rho_{\text {real }}\right)$.

A partir da equação 1 , estimou-se a porosidade de cada $\mathrm{CP}\left(\mathrm{P}_{\mathrm{CP}}\right)$ :

$$
P_{C P}(\%)=\left(1-\frac{\rho_{\text {val }}}{\rho_{\text {ral }}}\right) \times 100 \%
$$

Os resultados obtidos a partir do procedimento descrito são ilustrados na Tabela 2, juntamente com os teores de ar incorporado no estado fresco. Além disso, são apresentados os volumes de água utilizados na mistura das argamassas.

A partir dos dados da Tabela 2 foi plotado o gráfico apresentado na Figura 7, ilustrando a relação entre a porosidade do corpo-de-prova e o teor de ar incorporado mais o teor de água utilizado no amassamento. Visto que essa relação é linear e diretamente proporcional, com coeficiente angular 0,99, pode-se inferir que todo ar incorporado no material no estado fresco foi responsável pela alteração na resistência mecânica e no módulo de elasticidade dos materiais.

\section{Resistência mecânica}

A resistência mecânica está relacionada com a capacidade das argamassas de resistirem a uma força aplicada, podendo fornecer informações a respeito da rigidez do revestimento. O tipo de material utilizado na composição, o teor de ar incorporado, o teor de cimento, a relação água/cimento e a porosidade são variáveis que influenciam diretamente no valor dessa propriedade mecânica. A Figura 8 ilustra a variação da resistência a tração na flexão em três pontos para as três argamassas estudadas, em função da variação no teor de ar incorporado no estado fresco.

\begin{tabular}{|c|c|c|c|c|c|c|}
\hline $\begin{array}{c}\text { Argamassa } \\
\text { (teor de água) }\end{array}$ & Misturador & $\begin{array}{c}\text { Tempo de } \\
\text { mistura (min) }\end{array}$ & $\begin{array}{c}\text { Ar incorporado } \\
(\%)\end{array}$ & $\rho_{\mathrm{vol}}\left(\mathrm{g} / \mathrm{cm}^{3}\right)$ & $\rho_{\text {real }}\left(\mathrm{g} / \mathrm{cm}^{3}\right)$ & $\mathbf{P}_{\mathrm{CP}}(\%)$ \\
\hline \multirow{6}{*}{$\begin{array}{c}1 \\
(16,25 \%)\end{array}$} & \multirow{3}{*}{$\mathrm{EH}$} & 2 & 19,9 & 1,66 & 2,60 & 36,2 \\
\hline & & 4 & 21,1 & 1,60 & 2,64 & 39,4 \\
\hline & & 6 & 21,3 & 1,56 & 2,60 & 40,0 \\
\hline & \multirow{3}{*}{ B } & 2 & 17,5 & 1,71 & 2,65 & 35,5 \\
\hline & & 4 & 22,2 & 1,58 & 2,63 & 39,9 \\
\hline & & 6 & 25,5 & 1,51 & 2,67 & 43,4 \\
\hline \multirow{6}{*}{$\begin{array}{c}2 \\
(15,25 \%)\end{array}$} & \multirow{3}{*}{ EH } & 2 & 31,0 & 1,47 & 2,79 & 47,3 \\
\hline & & 4 & 36,6 & 1,36 & 2,70 & 49,6 \\
\hline & & 6 & 41,0 & 1,26 & 2,65 & 52,5 \\
\hline & \multirow{3}{*}{ B } & 2 & 23,4 & 1,61 & 2,63 & 38,8 \\
\hline & & 4 & 26,1 & 1,55 & 2,67 & 41,9 \\
\hline & & 6 & 28,5 & 1,53 & 2,68 & 42,9 \\
\hline \multirow{6}{*}{$\begin{array}{c}3 \\
(13,25 \%)\end{array}$} & \multirow{3}{*}{ EH } & 2 & 22,0 & 1,77 & 2,66 & 33,5 \\
\hline & & 4 & 29,9 & 1,61 & 2,71 & 40,6 \\
\hline & & 6 & 35,3 & 1,44 & 2,67 & 46,1 \\
\hline & \multirow{3}{*}{ B } & 2 & - & - & - & - \\
\hline & & 4 & 11,3 & 1,97 & 2,65 & 25,7 \\
\hline & & 6 & 14,6 & 1,92 & 2,65 & 27,5 \\
\hline
\end{tabular}

Tabela 2 - Densidade volumétrica, densidade real e porosidade dos CPs, calculados para estimar a estabilidade do ar durante a moldagem 


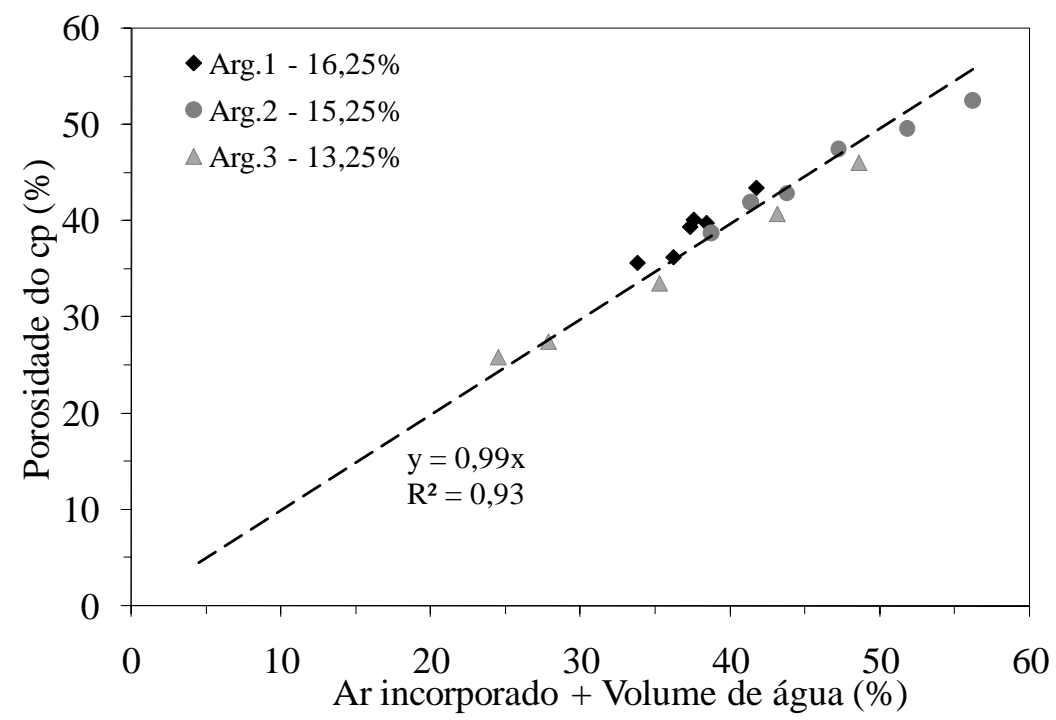

Figura 7 - Avaliação da estabilidade das bolhas durante a moldagem

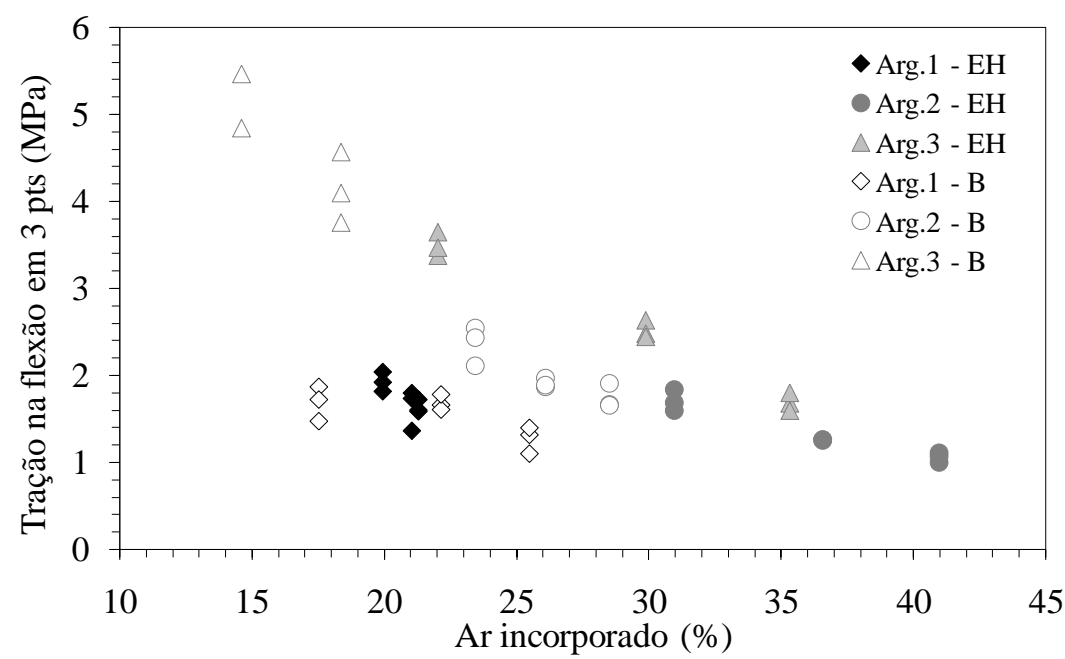

Figura 8 - Resistência mecânica das argamassas após cura por 14 dias a $23^{\circ} \mathrm{C}$ (7 dias em câmara úmida e 7 dias em câmara seca)

Nota-se que a variação na incorporação de ar foi a maior responsável pela alteração na resistência mecânica das argamassas. No entanto, para teores semelhantes de ar, a argamassa composta por maior quantidade de finos apresentou maior resistência mecânica. Provavelmente, a maior quantidade de material mais fino representou maior quantidade de aglomerante, responsável pelo desenvolvimento da rigidez do material.

As Argamassas 2 e 3 misturadas na betoneira apresentaram maiores resistências que as misturadas no equipamento EH. Por outro lado, no caso da Argamassa 1 esse fato não foi observado, ilustrando que cada argamassa se comportou de forma distinta em relação ao equipamento utilizado.

A grande variação na resistência mecânica, provocada pela alteração no tipo de misturador e tempo de mistura, ilustra o tamanho do problema enfrentado nas obras, pois as argamassas aplicadas apresentam diferenciadas propriedades no estado endurecido e, conseqüentemente, surgem diferentes desempenhos dos revestimentos aplicados.

\section{Módulo de elasticidade}

O módulo de elasticidade está relacionado ao comportamento elástico do revestimento, podendo fornecer informações a respeito da deformabilidade do material. Segundo Callister (1991), a porosidade tem uma influência deletéria sobre as propriedades elásticas dos materiais, e o módulo de elasticidade (E) decresce com a fração de volume de poros $(\mathrm{P})$ de acordo com a equação 2: 
$E=E_{0}\left[1-1,9 P+0,9 P^{2}\right]$

onde $\mathrm{E}_{0}$ é o módulo de elasticidade de material não poroso.

Segundo o referido autor, os poros são concentradores de tensões e reduzem área de seção reta através da qual uma carga é aplicada.

Conforme ilustrado anteriormente, o ar incorporado durante o estado fresco se manteve no corpo-de-prova após a moldagem e, por isso, as alterações geradas pelas alterações no tempo de mistura e tipo de equipamento se refletiram no módulo de elasticidade, conforme ilustrado na Figura 9.

As amostras que incorporaram menores quantidades de ar, apresentaram maiores módulos de elasticidade.

Da mesma forma que para a resistência mecânica, o aumento no teor de ar foi responsável pela redução de E. Além disso, a maior quantidade de aglomerante também foi responsável pelo aumento no módulo para argamassas com semelhantes teores de ar incorporado, ilustrando o impacto da falta de controle do processamento nas propriedades das argamassas após o endurecimento.

\section{Conclusões}

Após a discussão dos resultados, pode-se concluir que: (a) mesmo com o controle preciso da dosagem de seus constituintes, as argamassas industrializadas são sensíveis ao tipo de equipamento e tempo de mistura;

(b) existe uma tendência linear entre a incorporação de ar e o tempo de mistura. Quanto maior foi o tempo de processamento, maior foi o volume absoluto de ar incorporado;

(c) apesar de o teor de ar ter variado em função do tipo de equipamento, não houve uma tendência clara entre a incorporação de ar e o equipamento mistura;

(d) a partir do ensaio de reometria rotacional, foi possível quantificar as diferenças nas energias de mistura e notou-se que a Argamassa 3 necessitava de maior energia para ser processada. Por isso, após o processamento na betoneira, no menor tempo de mistura utilizado, a argamassa não se apresentou apropriada para o uso, devido à baixa eficiência do misturador;

(e) a variabilidade no ar afetou as propriedades das argamassas após o endurecimento e os valores de resistência mecânica e módulo de elasticidade reduziram em função do aumento no tempo de mistura; e

(f) pode-se inferir que uma alternativa para se reduzir a variabilidade do teor de ar em obra e, conseqüentemente, diminuir a variação da qualidade do revestimento é o desenvolvimento de formulações com mínima sensibilidade ao processo de mistura.

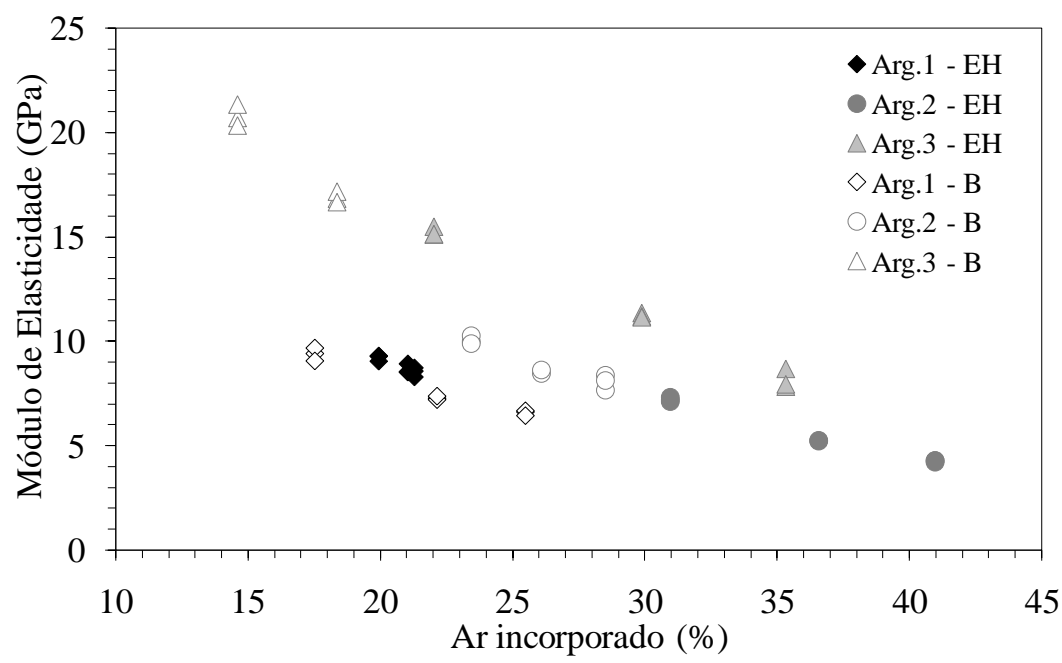

Figura 9 - Módulo de elasticidade das argamassas após cura por 14 dias a $23^{\circ} \mathrm{C}$ ( 7 dias em câmara úmida e 7 dias em câmara seca) 


\section{Referências}

ALVES, N. J. D. Avaliação dos Aditivos Incorporadores de Ar em Argamassas de Revestimento. 2002. 175 f. Dissertação (Mestrado em Engenharia Civil) - Escola de Engenharia, Universidade de Brasília, Brasília, 2002.

\section{ASSOCIAÇÃO BRASILEIRA DE NORMAS} TÉCNICAS. NBR 13278: argamassa para assentamento em paredes e revestimentos de paredes e tetos: determinação da densidade de massa e do teor de ar incorporado: método de ensaio. Rio de Janeiro, 2002.

\section{ASSOCIAÇÃO BRASILEIRA DE NORMAS} TÉCNICAS. NBR 13279: argamassa para assentamento em paredes e revestimentos de paredes e tetos: determinação da resistência compressão: método de ensaio. Rio de Janeiro, 2005.

\section{BRITISH STANDARDS INSTITUITION. BS}

1881: testing concrete recommendations for measurement of velocity of ultrasonic pulses in concrete. Londres, 1986.

CALLISTER, W. D. Materials Science and Engineering: an introduction. Nova York: John Wiley \& Sons, 1991.

CARASEK, H.; SCARTEZINI, L. M. B. Evolução da Resistência de Aderência dos Revestimentos de Argamassa Mista. In: SIMPÓSIO BRASILEIRO DE TECNOLOGIA DAS ARGAMASSAS, 3., Vitória, ES, 1999. Anais... Vitória: Antac, 1999. v. 2.

CASALI, J. M. et al. Efeito da Incorporação de Ar nas Propriedades de uma Argamassa Industrializada para Assentamento de Blocos de Concreto para Alvenaria Estrutural. In: SIMPÓSIO BRASILEIRO DE TECNOLOGIA DAS ARGAMASSAS, 5., São Paulo, SP, 2003. Anais... São Paulo: Antac, 2003.

CHIA, K. S.; ZHANG, M. H. Workability of AirEntrained Lightweight Concrete from Rheology Perspective. Magazine of Concrete Research, v. 59, n. 5, p. 367-375, jun. 2007.

CINCOTTO, M. A. et al. Massa Crítica pela Qualidade. Techne, v. 41, n. 100, jun. 1999. Disponível em: <www.cspublisher.com/admin/produtos/PTE/enge nharia-civil/41/artigo32197-1.asp > . Acesso em: 26 set. 2008 .
DU, L.; FOLLIARD, K. J. Mechanisms of Air Entrainment in Concrete. Cement and Concrete Research, v. 35, n. 8, p. 1463-1471, 2005.

FERRARIS, C. F. Concrete Mixing Methods and Concrete Mixers: state of the art. Journal of Research of the National Institute of Standards and Technology, v. 106, n. 2, p. 390-399, mar./abr. 2001.

MONTE, R.; UEMOTO, K. L.; SELMO, S. M. S. Qualificação de Aditivos Incorporadores de Ar para Argamassas de Assentamento e Revestimento. In: SIMPÓSIO BRASILEIRO DE TECNOLOGIA DAS ARGAMASSAS, 5., São Paulo, SP, 2003. Anais... São Paulo: Antac, 2003.

PERRY, R. H. Perry's Chemical Engineers' Handbook. $7^{\text {th }}$. Nova York: McGraw-Hill, 1997. cap. 18.

ROMANO, R. C. O. et al. Efeito do Tempo de Mistura nas Propriedades de Argamassas com Ar Incorporado. In: SIMPÓSIO BRASILEIRO DE TECNOLOGIA DAS ARGAMASSAS, 7., Recife, PE, 2007. Anais... Recife: Antac, 2007a.

ROMANO, R. C. O. et al. Impacto do Uso de Incorporador de Ar nas Propriedades Reológicas de Argamassas. In: SIMPÓSIO BRASILEIRO DE TECNOLOGIA DAS ARGAMASSAS, 7., Recife, PE, 2007. Anais... Recife: Antac, 2007b.

ROMANO, R. C. O. et al. Sensibilidade de Argamassas de Revestimento ao Procedimento de Mistura. In: SIMPÓSIO BRASILEIRO DE TECNOLOGIA DAS ARGAMASSAS, 8., Curitiba, PR. Anais... Curitiba: Antac, 2009.

SURYAVANSHI, A. K.; SWAMI, N. R. Development of Lightweight Mixes Using Ceramic Microspheres as Fillers. Cement and Concrete Research, v. 32, n. 11, p. 1783-1789, nov. 2002.

\section{Agradecimentos}

Os autores agradecem à Capes e ao Consórcio Setorial para Inovação em Tecnologia de Revestimentos de Argamassa (Consitra), pelo apoio durante a realização do trabalho. 